\title{
Las Narraciones Diferentes del Parto: Las Geometrías Relacionales
}

\author{
Serena BRIGIDI* \\ Universitat Rovira i Virgili, Tarragona, Spain
}

\begin{abstract}
Childbirth is no literary genre. As usual, in the story narrated childbirth is a process completed at the entrance or exit of some new characters. In most cases, also maternity is a purely descriptive element. Based on the analysis of selected fragments of literary and artistic works, it is proposed to rethink childbirth as a biographical-relational event. In it, in terms of aesthetic, ethical, social and political, entangle geometric figures that assume vulnerability as a human condition, as a category to build a relationship with the Alterity.
\end{abstract}

Keywords: Childbirths, maternities, relational geometries, alterities, vulnerabilities.

Resumen. No existe un género literario sobre el parto. De costumbre, este es un trámite finalizado a la entrada, o la salida, de unos nuevos personajes en la historia narrada y, la mayoría de las veces, también la maternidad es un elemento puramente descriptivo. A partir del análisis de fragmentos seleccionados de obras literarias y artísticas se propone re-pensar el parto como un evento biográfico-relacional. En él, en términos estéticos, éticos, sociales y políticos, se enredan figuras geométricas que

\footnotetext{
* Author's address:

Medical Anthropology Research Center, MARC

Universitat Rovira i Virgili

Av. Catalunya 35, 43002 Tarragona, Spain

E-mail serena.brigidi1@urv.cat
} 
asumen la vulnerabilidad como condición humana, como categoría para construir una relación con la Alteridad.

Palabras clave: Partos, maternidades, geometrías relacionales, alteridades, vulnerabilidades.

\section{1 ¡Shhh, Silencio! No se Puede Escribir de Partos ni de Maternidades}

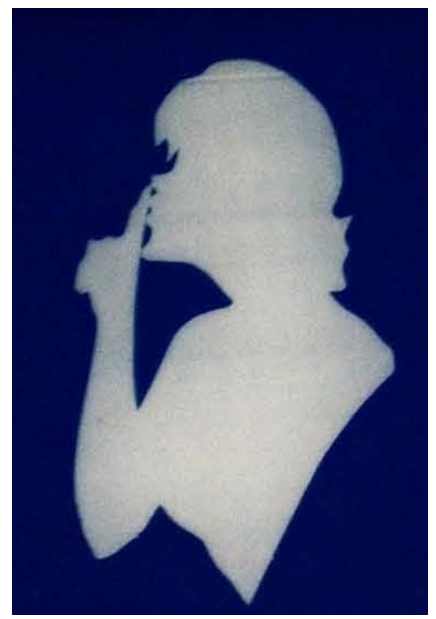

Fig. 1. Foto: (C) Serena Brigidi "Shhh", Callela de Mar, Barcelona.

No existe un género literario sobre el parto. Quizás se podría invertir un momento en reflexionar en torno a "lo de la maternidad" como categoría literaria; aunque si el parto es un trámite finalizado a la entrada, o la salida, de unos nuevos personajes en la historia narrada, la mayoría de las veces, la maternidad es un entorno, un elemento puramente descriptivo, un complemento, y raramente está descrita como un proceso ontológico de trasformación (Brigidi 2016) ${ }^{2}$.

${ }^{2}$ Algunas autoras que han tratado la maternidad en la literatura: Ginzburg, Fortún, Munro, Berlin, Paley. Consultar también Freixas (2009). 
Observamos más detalladamente la cuestión del biologicismo y del modelo ontológico individualista que, según mi percepción, hoy en día, siguen explicando las bases teóricas de la falta de profundidad, además en diferentes estructuras, en el discurso en torno a las maternidades. Así que, en primer lugar, persiste el determinismo biológico, al cual se hace referencia para pensar, describir y narrar la maternidad -y no las maternidades, pues se sigue reconociendo un único modelo homogéneo de madre (Brigidi 2016) - y representa una de las más temibles formas que ha asumido el mandado de género en la época contemporánea, donde el "consenso" y la "voluntad" (Donath 2016), el "deseo de" o la "casualidad" no toman cuerpo ${ }^{3}$, sustancia, ni reflexión literaria o interés académico. De tal modo que las mujeres no tenían -a veces, no tienen, tampoco hay que olvidarlo- otra posibilidad para figurar en sus vidas y en la de los demás que lo de ser madres. Una sucesión de: "hija de", "esposa de", "madre de". Precisamente "a través del Otro"4, la mujer toma un cuerpo, una forma de "protagonismo delegado a" y así se le garantiza una presencia -finalizada a, relegada a- en la escena y en la sociedad. La socióloga Donath, en su estudio en torno a las madres arrepentidas, observa cómo en determinados ambientes, el determinismo biológico parece superado en los discursos, pero no en los contenidos. Estas contradicciones modernas exploradas, como veremos, también por Lagarte, entre otras, se trasforman en una sutil "retórica de la elección", en el mantenimiento del "lenguaje de la naturaleza", o de una "voluntad institucionalizada" (Lagarte 2003; Donath 2016: 40-50). Incluso, otras autoras reflexionan sobre una "imaginación colonizada" (Tietjens 2001) y en "coacciones sociales" que hacen elegir si tener, o no tener, hijos (Himmelweit 1988). En otras palabras, seguimos viviendo en una época de "libertad condicional" (Donath 2016: 38) desde el momento en el cual una mujer es libre de ser madre, aunque de ella se espera siempre que opte por la elección acertada: es decir, serlo. De ahí los conflictos, las contradicciones y la incapacidad de definirse, narrarse y reconocerse como mujeres si no es en oposición a la elección de ser madre: como si la epistemología humana estuviera fundada en la negación. The National Organization for Non-Parents,

${ }^{3}$ En mi opinión, otro mito de la maternidad: muchas veces, como ya visto por la cuestión migratoria, no existe un proyecto específico como lo definen los académicos (Brigidi 2009). En las sociedades occidentales, la variabilidad del cómo, por qué y para qué quedarse embarazadas es relevante y contempla también la ausencia de reflexión y de planificación, por ende, una casualidad.

${ }^{4}$ A pesar de reconocer la necesidad de usar un lenguaje que contemple el femenino y el masculino, en dicho contexto se ha optado por el uso del masculino genérico. 
actualmente llamada National Alliance for Optional Parenthood ${ }^{5}$ en EE.UU., el proyecto fílmico de Lunàdigas en Italia ${ }^{6}$, Soy mujer y no quiero tener hijos ${ }^{7}$ en España o Australian Childfree ${ }^{8}$ en Australia, son solo algunos ejemplos del extenso movimiento del child free, donde el fundamento ontológico consiste en la negación de ser madre y en la oposición a tener hijos (Brigidi 2016):

No existe, ni en la literatura de ficción, ni en la academia, el modelo que separe a la mujer que da la vida, de la mujer que simplemente vive por el puro placer de existir despojada ya de su función de hembra reproductora de la especie. (Belli 2014: 96).

Así que sigue actual la afirmación de la antropóloga feminista Mari Luz Esteban, la cual describe la maternidad como un campo privilegiado para comprobar la articulación entre ideología y cultura (2000: 207). Por eso, me parece preciso reconocer cómo la doctrina que persiste actualmente, también en los contextos occidentales, es la del determinismo biológico con todos sus matices $^{9}$. Cuanto expuesto explicaría también por qué las afirmaciones de Samanta Villar, periodista catalana, tras su libro Madre, hay más que una (2017), en torno al cuento idílico de la maternidad y su pérdida de calidad de vida, han generado un alboroto de comentarios negativos procedentes, sobre todo, de mujeres con hijos e implicadas con el proceso de crianza ${ }^{10}$ : aquí, la

\footnotetext{
${ }^{5}$ https ://en.wikipedia.org/wiki/National_Alliance_for_Optional_Parenthood

${ }^{6}$ http : //www.lunadigas.com/wpph/

${ }^{7}$ https : //www.facebook.com/NoHijos/

${ }^{8}$ https : //www.meetup.com/en - AU/vic-childfree/

${ }^{9}$ Del eurodiputado polaco Janusz Korwin-Mikke: ¿¿Sabe usted cuántas mujeres hay entre los primeros cien jugadores de ajedrez? Se lo diré: ninguna. Por supuesto, las mujeres deben ganar menos que los hombres porque son más débiles, más pequeñas, menos inteligentes" (http : //www.publico.es/politica/eurodiputadojustifica - mujeres - menos - inteligentes.html), o de la campaña HazteOír.org con mensajes contra "las leyes de adoctrinamiento sexual" con lemas como "Los niños tienen pene", "Las niñas tienen vulva", "Que no te engañen", "Si naces hombre, eres hombre" o "Si eres mujer, seguirás siéndolo" (http : //www.elmundo.es/f5/2017/02/28/58b522f4268e3ea2708b4715.html). Matices extremistas que tienen que ver con cuestiones de género y el papel (el valor, la función) de la mujer en nuestra sociedad.

${ }^{10}$ Entrevista del 29 de enero de 2017: "Tener hijos es perder calidad de vida" afirma en una entrevista con EFE y apostilla: "Yo no soy más feliz ahora de lo que era antes" http : //www.efe.com/efe/espana/gente/samanta-villar-tenerhijos - es - perder - calidad - de - vida/10007 - 3162925
} 
libertad condicionada que no permite a una mujer contar su experiencia y a las otras escucharla y aceptarla como narración diferente. Cabe destacar que estudiar las maternidades, cuando el pensamiento popular y científico se extiende sobre dicha ideología, requiere un esfuerzo mayor para encontrar mecanismos que resalten los discursos y no solo las categorías (por ejemplo: el Club de las Malas Madres ${ }^{11}$ ), discursos también internos a la misma investigadora, que puedan marcar, tanto a nivel ético, social como político, una vida más vivible (Butler 2002), una devolución social de la investigación (by/for/on women), una implicación encarnada (Brigidi, 2016). Asimismo, las contradicciones actuales y las diferencias, describen las normas culturales locales que no se pueden trasgredir de manera radical y total, pero que podemos subvertir mediante re-significaciones, a partir de actos cotidianos (Butler 2014). En otras palabras, no solo resulta importante definir, nombrar las situaciones, y comprenderlas, sino también ser conscientes de los riesgos que estas, en su excepción legal, ética e ideológicas, pueden representar (víctima, superviviente, etc.). En definitiva, lo que está ocurriendo con la violencia obstétrica es que, por una parte, se está visualizando y, por la otra, al entrar dentro de unas circunstancias en boga, se atribuyen categorías aún más rígidas a las personas implicadas, sin aportar beneficios o estrategias de mejora.

En segundo lugar, tenemos la ontología individualista, un ideal en absoluta compenetración con el determinismo biológico. Vamos a ver, el modelo individualista que, desde Kant hasta hoy, ha invadido el pensamiento sobre el cuidado, la crianza, el problema del sujeto-objeto (Lévinas 1984) ${ }^{12}$, inclusive dentro la filosofía feminista, ha reorganizado los discursos en torno a la responsabilidad hacia los otros ${ }^{13}$, el "estar con" y el "cuidar de", como graves ataques a la modernidad y a la libertad individual. Los otros, sobre todo si inermes, representan un evidente obstáculo a la carrera, al éxito profesional y personal, así como al bienestar individual. Así que, los conceptos fundamentales en las sociedades occidentales resultan ser: rectitud, autonomía ${ }^{14}$, dependencia, racionalidad y libertad (Forcades 2012). Aunque, con las maternidades existen vulnerabilidades; con ellas se evidencian, debido a que hay

${ }_{11}$ https : //clubdemalasmadres.com

12 En este sentido, además del pensamiento de Lévinas, me refiero también a la problemática que, desde siempre, ha atravesado el Arte.

13 Este discurso se puede aplicar también a una mascota o al medio ambiente, a los derechos cívicos y sociales, etc.

${ }^{14}$ En este sentido, Adriana Cavarero observa que deberíamos repensar la autonomía en términos de relacionalidad (2013: 24). 
vidas particularmente expuestas y precarias (Butler, 2014; Cavarero 2013). De tal manera que este sujeto autónomo, recto, riguroso que las sociedades occidentales demandan a partir del modelo patriarcal de rigor promovido por Kant, solo engendran formas de "sincretismo de género", sobre todo, en las mujeres:

Cuidar a los otros a la manera tradicional y, a la vez, lograr su desarrollo individual para formar parte del mundo moderno, a través del éxito y la competencia. El resultado son millones de mujeres tradicionales-modernas a la vez. Mujeres Atrapadas en una relación inequitativa entre cuidar y desarrollarse. (Lagarte 2003: 2).

Lo que emerge son mujeres enredadas con las contradicciones que empiezan ya con la idea de ser o no madre y se hacen eco durante el embarazo -"fue un tiempo de sentimientos contradictorios, desordenados, inquietantes. Sentimientos que escondí desde el principio" (Calero 2015: 31). Estilos de vida que nos quitan aliento y salud. A este propósito, Carme Valls suele recordar el estudio liderado por Marianne Frankenhauser del Instituto Karolinska (Frankenhauser et al. 1978; Valls 2009). Ella y su equipo demostraron que las mujeres ejecutivas en igualdad de trabajo con hombres ejecutivos presentan diferentes patrones de secreción de neurotransmisores que pueden causar hipertensión y que están relacionados con el sincretismo de género:

Durante las mañanas en el trabajo tenían unos niveles de adrenalina, noradrenalina y cortisol, mucho más bajos que sus compañeros, y unos niveles de tensión arterial que incluso disminuía cuando llegaban al trabajo. Por la tarde, al llegar a su hogar, los varones disminuían sus niveles de adrenalina, noradrenalina y cortisol y su tensión arterial, mientras que a las mujeres les aumentaban los niveles sobre todo de adrenalina, tres veces el nivel basal, y estos niveles persistían por la noche. Esta situación mantenida durante meses y años, condiciona riesgos cardiovasculares e hipertensión sobre todo de las 7 de la tarde a las siete de la mañana siguiente y esta hipertensión de predominio femenino, se relaciona con la doble jornada y el hecho de que a estas horas se debe continuar haciendo el trabajo doméstico, sean las mujeres ejecutivas, administrativas o amas de casa. Estas causas de hipertensión han permanecido invisibles porque se han investigado las causas de unas manifestaciones diferentes entre mujeres y hombres. (Valls 2009: 8-9). 
Ahora bien, observadas brevemente nuestras herencias, sus contemporáneas perversiones y las consecuencias en términos de salud que traspasan los cuerpos de las mujeres, mi objetivo consiste en analizar el parto - y, de consecuencia, las maternidades-, como un proceso ontológico de tras-formación a partir de algunas "narrativas diferentes" (Allende 1994). Como referente teórico comienzo con la idea de un modelo relacional, donde la categoría de relación permite repensar el parto no (solo) en términos de ruptura, exposición, vulnerabilidad y dependencia, conceptual y semánticamente vinculadas con las estructuras de la violencia (vulnus: herida), sino como categoría originaria y constitutiva del Ser. Pensamos en la reflexión de Lévinas cuando comenta que "el hombre está en situación aún antes de ser situado" (1984: 23). La vulnerabilidad que se trabaja es en la relación constante con el Otro, la Alteridad y el mundo circunstante (Butler 2014). Además, a partir de un marco conceptual amparados en la conciencia de género (Reckitt y Phelan 2005).

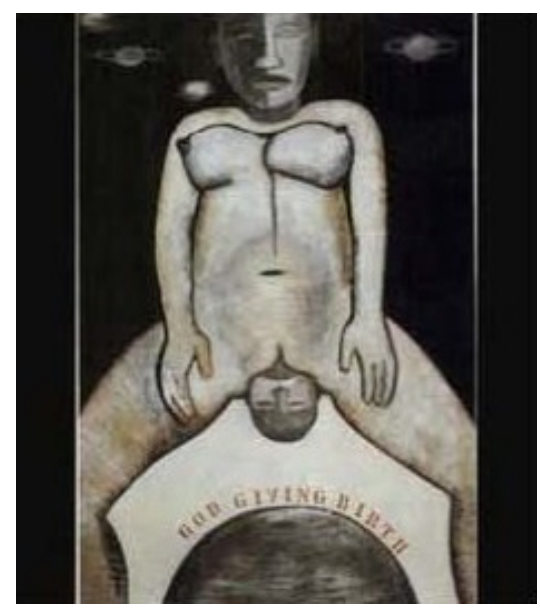

Fig. 2. Monica Sjöö (1968) God Giving Birth. Tras la exposición colectiva del 1973 en Londres, la policía acabó por enviarle un informe a la Fiscalía y se amenazó a Sjöö con interponer una demanda contra ella por blasfemia y obscenidad (Reckitt y Phelan, 2005).

Es decir, como esfera ontológica, como "criaturas vulnerables que materialmente, y a menudo en circunstancia de fuerte desplazamiento, se entregan la una a la otra" (Cavarero 2013: 24). Para realizar eso, me aprovecho de frag- 
mentos de obras literarias y artísticas que he ido guardando en los últimos años, donde el cuerpo, como proceso a través del cual conocemos, experimentamos y cambiamos el mundo, como campo de vulnerabilidad, acción y subversión, es también el terreno de la relación. Narraciones diferentes en las cuales el parto está experienciado, distante de la naturaleza patriarcal, del modelo capitalista o de la iconografía cristiana y occidental secular con la cual, aún, se representa, relata e historiza el parto.

\subsection{Dependencias Múltiples y Singulares}

Los hijos, como los libros, son viajes al interior de una misma en los cuales el cuerpo, la mente y el alma cambian de dirección, se vuelven hacia el centro mismo

de la existencia

(Allende 1994: 303)

El contexto social, cultural, educacional y económico, así como las experiencias subjetivas, la capacidad de análisis críticos, el encontrarse en una situación en la cual se otorguen concretamente los derechos de reconocimiento a las mujeres (dentro de sus modelos de familia de origen y política, en el contexto laboral y social) permitiría restablecer la idea de exposición al otro -"cuando estaba embarazada, todo mi ser era pura gestación" comenta Clara, la protagonista del libro de Calero (2015: 31) - de vulnerabilidad y de dependencia -"cuidaba y mimaba mi cuerpo al máximo, hasta el punto de albergar la impresión de que pertenecía al bebé, más que a mí misma" (Calero 2015: 31); "¿Y mi entereza? Hechas trizas por una sola idea: el miedo terrible a perder el control" (Calero 2015: 146)- en un modelo relacional, una geografía compleja donde la sumisión, la culpa y la ruptura del Ser no prevalecerían o no ejercieran el control. De tal manera, se podría liberar el parto, el proceso de embarazo, de crianza, del paradigma de la violencia. Esta categoría relacional no quiere reconvertir al sujeto en otro descompuesto, redefinido a partir del concepto de madre "sujetas-en tanto-que", como observa Brigitte Vasallo $(2014)^{15}$. O como relata Clara:

Es difícil encontrar sentido al dolor cuando está dentro y toda tú eres un quejido; fisiológico como dicen, pero un quejido, por muy

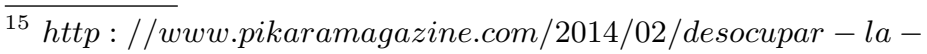
maternidad/\#sthash.NdIVGZkG.dpuf 
afable que sea. Acostumbrada a interpretar la existencia desde el pensamiento a través de la literatura, no contaba con el sentimiento y el desgarro de un cuerpo que identifico como parte indisolubles de mí. Vila Matas lo expresa genialmente en su "El Mal de Montano": "la literatura me ha permitido siempre comprender la vida. Pero precisamente por ello, me dejas fuera de ella." (Calero 2015: 141).

Las ideas críticas hacia las maternidades pasan por un modelo ontológico individualista en el cual incluso la concepción del cuerpo está pensada como una entidad endogámica, una "singularidad corporal" (Cavarero 2013: 114), encerrada en sí, de tal manera que la inclinación a la Alteridad está interpretada dentro de un modelo abnegado y de sacrificio. No acaso Judith Butler pregunta: "¿somos capaces de entender el cuerpo como medio de transmisión? El cuerpo es un lugar en el que la historia pasa del uno al otro" (Butler 2014: 105). Adriana Cavarero lo diseña brillantemente, en variados textos, analizando autores de diversas épocas históricas:

El modelo relacional, de hecho, no provee algunas simetrías, sino un continuo intrincarse de dependencias múltiples y singulares, a veces extremas, en el acentuar la relación desequilibrada de los protagonistas en la escena y, así, ejemplar. Una de estas [...] es a menudo vinculada con la "escena primaria" que ve el infante en condición de absoluta y unilateral dependencia de los otros, o sea, como sería obvio decir, de la madre. (Cavarero 2013: ${ }^{16}$.

Ella sigue analizando cómo la figura del infante sí es utilizada para ejemplificar la ontología relacional, pero a la madre, debido al estereotipo oblativo, latita, se la pierde en la reflexión, cuando a nivel ontológico, ético y político debería generar un análisis profundo. De ahí quiero empezar, de esa escena primaria, el parto narrado, experienciado, como momento para analizar un proceso ontológico de tras-formación y de relacionalidad.

$\overline{16}$ Traducción al castellano de la autora. 


\section{El Parto Narrado: "¡Mi Madre ha Tenido la Vagina!"}

-Clara, cuando crezcas y tengas hijos, lo entenderás. Entenderás muchas cosas

(Calero 2015: 14)

Según mi hija pequeña, Aida, yo antes de parirla no tenía vagina ${ }^{17}$. Había parido a su hermana y a su hermano a través de una cesárea programada. La cicatriz de esto resuena en mi barriga re-significándola; cambiándole aspecto y forma. Una línea profunda, sutil, de trazo incierto, casi fragmentada, que atraviesa mi bajo vientre de un extremo a otro. Imposible no notarla cuando estoy desnuda. Ni la he ocultado ni lo quiero hacer. Esta estría blanca que sobresale de mi piel, de bordes levemente redondos, es un elemento cartográfico relacional en el cual la historia de mis hijos mellizos, y la mía como madre, empieza. Una evidencia carnal y simbólica. De allí han salido, de allí nos vimos, nos olimos, nos tocamos. De allí mi piel se rompió. De allí nacen sus narraciones como personas separadas de mi cuerpo y entre ellos, no obstante, enredados con una geografía relacional, permitidme decir (o creer), eterna. Tres años más tarde, su hermana nació con un parto vaginal, respetado y sin intervencionismo. A menudo Aida explora curiosa mi cuerpo desnudo en busca de signos que, como en el caso de su hermana y su hermano, evidencien su nacimiento. Y no los encuentra. En comparación con la línea blanca que me corta el bajo vientre, ella procede de un lugar que define como "más oscuro". Esa porción de cuerpo poco expuesta y visible -escondida entre las piernas, de color moreno y caracterizada por la presencia de vello- le resulta menos acogedora que la barriga. En efecto, ella misma tiene que agacharse para observarla. Así que un día ha supuesto, con mucho énfasis, con una pizca de orgullo, que yo -antes de ella- no tenía vagina: “Sino por qué Gaia y Dídac no recorrieron el mismo canal para nacer?"

La vagina me vino con mi hija pequeña, debido a su manera "original" de venir al mundo. De ese lugar oscuro y escondido, íntimo, nace su historia como persona y yo, indiscutiblemente, he re- significado mi vagina.

Lo que quiero observar con ese relato auto-referencial es que el parto es un testimonio, una memoria. Una historia, una narración, un relato. En parte, este concepto ha sido analizado en el trabajo Altres Naixements (Brigidi et al. 2017). Un texto elaborado siguiendo las percepciones sobre el parto de

$\overline{17}$ Aida, cuando narró su historia de parto, tenía 4 años. 


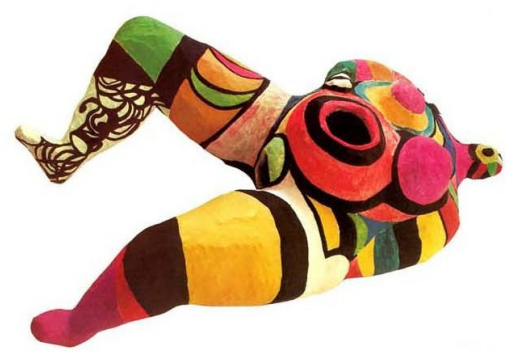

Fig. 3. Niki de Saint-Phalle (con Jean Tinguely y Per-Olof Ultvedt), (1966). Hon. Una mujer embarazada de $28 \times 9 \times 6$ metros, penetrables desde la vagina por el púbico. Un cuerpo habitado (Martín 2007).

niños de 3 a 10 años. Dieciocho dibujos y una obra en papel marché, más los relatos sintéticos de los partos, protagonizaron dos exposiciones, diversas charlas y debates en la capital catalana que encarnaron el proyecto de Altres Naixements. Lo que ha emergido de las obras ha sido una percepción normativa del parto altamente medicalizado, incluso cuando el artista había nacido de forma fisiológica. En algunos casos, el parto no existe, pasando del estado de embarazo de la madre al bebé ya separado, fuera del útero. El cuerpo de la madre es una línea que corta su barriga, una cesárea casi omnipresente. Estos dibujos nos hicieron plantearnos diversas cuestiones; en primer lugar, si narramos a nuestros hijos cómo han nacido y cómo contestamos cuando ellos nos preguntan, sucesivamente, cómo estamos representando el parto en los recursos audiovisuales y digitales que nos rodean y, finalmente, qué papel tiene la endoculturación en la construcción de dicha representación. En efecto, muchas madres nos han comentado que no han participado en Altres Naixements porque no habían hablado de estos temas, que aún no tocaba que "de alguna manera" tenía que ver con esta educación sexual que se considera más apropiada para edades más avanzadas. Y allí queda, como asignatura pendiente. Cabe destacar que muchas de ellas se preguntan en torno a su propio nacimiento cuando están embarazadas la primera vez (Cardús 2015). Como si el nacimiento no fuera parte de la biografía de cada una de nosotras. Así que, la narración del parto ${ }^{18}$, como momento ontológico relacional

${ }_{18}$ El relato de cada uno de los actores presentes en el parto: madre, pareja, doula, profesionales, fotógrafa, etc. está determinada por la presencia, en el sentido Demartiniano del término, del grado de implicación con la madre y resulta siempre periférico a lo de ella. Esta es la protagonista de la narración. La otra o las otras 
de presencia, está ocultado al nacido o minimizado, por la misma protagonista, a los detalles más periféricos de la experiencia del parto/nacimiento: horario y peso del bebe. A pesar de vivir en un entorno social contradistinto de una estética sexualizante y sexualizada, no existe una problematización, argumentación de estos temas, ni un discurso centrado en la educación afectivo y sexual ni en el placer. Y el parto, como observa Schallman, "es un hecho genital y absolutamente sexual" (2007: 52). Además, cabe pensar cómo, en la experiencia occidental, el cuerpo se conoce, se percibe, se transmite y se siente -abnegación y sacrificio, si hablamos del cuerpo materno-. Este proceso experiencial de descubrimiento y conocimiento corporal suele ocurrir a través del dolor, no del placer. Esto genera importantes repercusiones también en la formulación de qué es la salud. "La salud no existe, es un cielo que no forma parte de la existencia: los seres humanos solo podemos vivir enfermos" (Barrera 2006: 83).

Otra cuestión relevante en Altres Naixements consiste en reconocer cuándo y por qué el parto no está narrado. Mi opinión al respecto es que el parto no es narrado cuando hay violencia, malas experiencias, si no hay respeto, reciprocidad, si existen o se producen traumas, miedos, terrores, cuando se provocan secuelas tras las intervenciones, cuando no hubo protagonismo, sino muchas y largas pasividades. No se relata el parto todas las veces en las que se anula el carácter ontológico del Ser, la historia de una persona. En todos estos casos, se oculta la narración:

No, no fue felicidad por el nacimiento de mi hijo fue solo un alivio, por fin sabía que la tortura a mi mujer se había acabado. Fue la única razón de sentirme feliz. (Greg 2016). ${ }^{19}$

En muchas otras ocasiones, no se transmite un parto a los otros, cuando se generan sensaciones de incoherencias y, por ende, vergüenza:

[...] porque me asalta un sentimiento parecido a la vergüenza siempre que pienso en aquellas horas. Quizás porque utilicé demasiadas veces la palabra debería o porque la mujer fuerte, orgullosa, audaz, sabelotodo, se derrotó con sus propias armas. No lo sé. (Calero 2015: $13)$.

protagonistas, las bebés, personas que no pueden detener el recuerdo sino como mera experiencial corporal.

${ }^{19}$ Greg es el esposo de mi informante. 
y de culpa, por temor de atemorizar a las demás, porque las cosas malas no se cuentan en cenas o reuniones familiares:

Todo lo que había leído, lo que había aprendido, lo que me habían contado, resbaló como lluvia en un cristal. Pienso que no era el dolor lo que más me asustaba, sino la pérdida de control que iba notando en cada contratación. Lucía, una amiga de la Facultad, se sentía tan avergonzada de su conducta, del animal que se le despertó ese día, que jamás consintió contarme su experiencia. (Calero 2015: 166).

Existen silencios, cuando hay miedo, dolor, falta de control, que se traducen en una sensación de baja autoestima y soledad:

Todo se trastocó desde el principio. Interpreté mal las señales. Nadie me ayudó a entender. Las clases de educación maternal, patéticas y lastimosas, sirvieron para sofocar mi frágil autoestima en este mundo desconocido llamado maternidad. El dichoso delegado de salud, del que hablaba la enfermera, me dejó a la intemperie, a mí y al resto de embarazadas. Algunos grupos de mujeres son invisibles en ciertos paisajes. Todo sigue igual en el siglo XXI. Una evidencia insoportable. (Calero 2015: 128).

Las contracciones seguían una tras otra, sin descanso, como las olas del mar. Unas se deslizaban sin apenas montarse y otras rompían contra mi cuerpo rugiendo con toda su fuerza. No podía hacer nada, ni para acelerar ni por ralentizar. [...]. Mi cuerpo se rendía de cansancio. Tras la contracción, el dolor permanecía agazapado, invisible; una presión continua, como si tuviera un elástico encima del pubis. (Calero 2015: 141).

Como último, no se relata si el parto vivido se corresponde con lo ideal de lo que debería ser un parto en el imaginario colectivo y social (Brigidi 2016). Cardús, en su trabajo etnográfico sobre el miedo al parto y la narrativa transgeneracional (2015), observa cómo las mismas mujeres definían los relatos de los familiares como narraciones "frías", pobres en detalles reales sobre el parto. También otra autora señala la queja de las madres debido a la falta de información auténtica y efectiva, observando que esta es incompleta, poco compleja y verídica sobre el nacimiento (Callister 2004). En efecto, el 
desconocimiento sobre el parto es un tema que emerge "muy a menudo" en los relatos y en literatura:

En las horas que pasó al lado de su hermana aprendió más que en todos los años de estudio en la escuela del pueblo. Renegó como nunca de sus maestros y de su mamá por no haberle dicho en ninguna ocasión lo que se tenía que hacer en un parto. (Esquivel 1989: 29).

Tita había visto nacer algunos animales, pero esas experiencias de nada le servían en estos momentos. En aquellas ocasiones solo había estado de espectadora. Los animales sabían muy bien lo que tenían que hacer, en cambio, ella no sabía nada de nada. Tenía preparadas sábanas, agua caliente y unas tijeras esterilizadas. Sabía que tenía que cortar el cordón umbilical, pero no sabía cómo ni cuándo ni a qué altura. Sabía que había que darle una serie de atenciones a la criatura en cuanto arribara a este mundo, pero no sabía cuáles. Lo único que sabía es que primero tenía que nacer, iy no tenía para cuándo! Tita se asomaba entre las piernas de su hermana con frecuencia y nada. Solo un túnel obscuro, silencioso, profundo. [...] cuando por fin despegó los párpados el obscuro túnel, de un momento a otro se transformó por completo en un río rojo, en un volcán impetuoso, en un desgarramiento de papel. La carne de su hermana se abría para dar paso a la vida. Tita no olvidaría nunca ese sonido ni la imagen de la cabeza de su sobrino saliendo triunfante de su lucha por vivir. No era una cabeza bella, más bien tenía forma de un piloncillo, debido a la presión a que sus huesos estuvieron sometidos por tantas horas. Pero a Tita le pareció la más hermosa de todas las que había visto en su vida. (Esquivel 1989: 30).

\subsection{Geografías del Parto}

Silencio antes de nacer, silencio después de la muerte, la vida es puro ruido entre dos insondables silencios

(Allende 1994: 304)

Cuando he adaptado las ideas de Adriana Cavarero en torno a las geografías y la asunción de la vulnerabilidad como paradigma del humano al parto, es decir, he utilizado el pensamiento de la diferencia sexual de ella elaborado como marco teórico y conceptual para repensar al parto, la primera 
novela que me ha venido a la mente ha sido Paula, de Isabel Allende (1994). Un libro que amo y re-leo frecuentemente y que me acompaña desde hace más de veinte años. Me fascinan el tejido de relaciones, redes e hilos que la autora trenza, cómo esas se solapan y se rompen, en la incierta línea de memoria, "La memoria también es facultad de olvidar" (Ferrarotti 2007: 109). Ella narra sobre un tiempo anacrónico, del sabor a sangre, tierra y agrio. Y todas estas historias, tras-pasan el cuerpo de la autora.

Como había traído sus hijos al mundo en la casa, ayudada por su marido y una comadrona, se desconcertó con los modernos métodos de la clínica. Atontaron a la parturienta de un solo pinchazo, sin darle oportunidad de participar en los acontecimientos, y apenas nació el bebé lo trasladaron a una guardería aséptica. Mucho después, cuando se disiparon las brumas de la anestesia, informaron a la madre que había dado a luz una niña, pero que de acuerdo con el reglamento solo podría tenerla consigo a las horas de amamantarla. [...] mientras yo chillaba de hambre en otro piso, mi madre forcejeaba furiosa, dispuesta a recuperar a su hija por la violencia, en caso necesario. Acudió un doctor, diagnóstico una crisis histérica, le colocó otra inyección y la dejó dormida por doce horas más. Para entonces mi abuela estaba convencida que se encontraban en la antesala del infierno y apenas su hija espabiló un poco, la ayudó a lavarse la cara con agua fría y ponerse la ropa. -Hay que escapar de aquí [...] (Allende 1994: 23).

En estos tiempos modernos, como relata Allende, hablar de geografías del parto podría resultar sobradamente sencillo. En las sociedades occidentales, en particular, en España ${ }^{20}$, el parto se realiza en un hospital público o privado. Este se produce mayoritariamente en litotomía: la mujer tumbada boca arriba y con las piernas abiertas, sostenidas por dos estribos (la simbología de la escultura Hon). El vientre descubierto, la cadera en flexión, la pelvis rotada al exterior ${ }^{21}$ y expuesta a los demás, los profesionales del parto, con los cuales, a menudo, no se establece una relación significativa ni una reciprocidad: ginecólogos, matronas, enfermeras, anestesistas, pediatras y auxiliares.

${ }^{20}$ Por cuestiones de estilo, he optado por no reportar datos epidemiográficos sobre partos en España. Se reenvía a las páginas de: Dona Llum, El Parto es Nuestro, Observatorio de la Violencia Obstétrica y otros artículos míos.

${ }^{21}$ Abducción y rotación externa. 
Más que geografías hablaríamos de una única posición. Una línea horizontal que encarna una extrema vulnerabilidad y que, además, en sus versiones más violentas, contempla incluso la inmovilidad: continuas monitorizaciones - cables que atan el vientre de la mujer impidiendo que se levante-, inoculación de drogas sintéticas -que, si el palo donde se coloca el goteo no tienen ruedas, obligan a la misma posición- y, a veces, los artos superiores del cuerpo, atados a la camilla -algunos partos por cesáreas-. Inmovilidad también dada por el peso de un profesional de la salud encima de la barriga que aplasta y comprime, rompe y desgarra el interior de la mujer y de su feto, o por el corte de la vagina, una mutilación con secuelas, a veces, irreversibles, o por la entrada de las palas para mover el feto en la vía del parto:

Nicolás nació sin un solo pelo, con un cuerno en la frente y un brazo morado; el unicornio fue producto de los fierros que utilizaron para arrancármelo en el momento del parto. (Allende 1994: 184).

o de ventosas para controlar en el camino el feto. También, las disposiciones precisas otorgadas por los profesionales de la salud, según las necesidades o los tiempos establecidos del sistema, sobre cuándo y cómo empujar. Simbólicamente, casi volver a encontrar una analogía entre la mujer y el inerme, el bebé, a punto de nacer. Así que el testimonio del nacimiento se transforma en una narración de pasividad ("me han hecho parir") ${ }^{22}$, de pérdidas, de robos:

La cesárea anterior me había privado de un rito único que solo las hembras de los mamíferos comparten. El proceso alegre de engendrar un niño, la paciencia de gestarlo, la fortaleza para traerlo a la vida y el sentimiento de profundo asombro en que culmina, solo puedo compararlo al de crear un libro. (Allende 1994: 303).

Nada así había experimentado cuando naciste tú, Paula, porque fue una limpia cesárea. Con tu hermano no hubo nada romántico, solo esfuerzo, sufrimiento y soledad. No había oído que los padres podrían tener alguna participación en el evento, y por lo demás Micheal no era

${ }^{22}$ María, 40 años. Tres hijos. Médico. 2017. Francisca Fernández, activista y abogada de El Parto es Nuestro recuerda en un post en Facebook (3 de marzo de 2017 a las 11.52h) como "Parir a la mujer", "hacerle el parto" forman parte del diálogo clásico del personal de un paritorio y cómo estas expresiones son sexistas y violentas. Los trabajos etnográficos de los últimos años realizados en los paritorios, resaltan cómo las mujeres aprenden a encarnar estas expresiones para hablar de sus partos. 
el hombre ideal para ayudar en ese trance, desfallece a la vista de una hoja o de sangre. El parto me parecía entonces un asunto estrictamente personal, como la muerte; no sospechaba que mientras yo parecía sola en una pieza del hospital, otras mujeres de mi generación daban a luz en sus casas en compañía de una matrona, el marido, los amigos y un fotógrafo, fumando mariguana y con música de los Beatles. (Allende 1994: 184).

Celia tuvo su primer niño en Caracas, atontada de drogas y sola porque no dejaron entrar a su marido al pabellón. Ni ella ni el bebé fueron los protagonistas del evento, sino el médico, sumo sacerdote vestido de blanco y enmascarado, quien decidió cómo y cuándo oficiaría la ceremonia; indujo el nacimiento el día más conveniente en su calendario porque deseaba irse a la playa por el fin de semana, así fue también cuando nacieron mis hijos hace más de veinte años, los procedimientos han cambiado poco, por lo visto. (Allende 1994: 248).

o de muerte:

Reconoce ese frío por su desmesura. Le recuerda el que sintió viendo morir a su madre o el que la hizo tiritar después de los partos, ese que los médicos atribuyen a una reacción a la anestesia epidural. Después del segundo hijo ella había llegado a la conclusión de que ese hielo se debía al miedo y no a reacciones químicas. Era el miedo a la muerte. (Belli 2014: 43).

En definitiva, el parto se recuerda a pesar de representar un momento circunscrito, limitado, en la vida de una persona; resulta ser un recuerdo significativo y, como hemos visto, no por lo bello que es o debería ser, no por cuestiones románticas ni ideológicas. Sino porque allí se tejen relaciones, se produce un cambio (no necesariamente este cambio pasa por el concepto de cuidado, que más bien responde a una construcción social y cultural). Un cambio que tiene que ver con la acción, esa facultad política por excelencia que se radica ontológicamente en el hecho de la natalidad (Cavarero 2013; Arendt 2006). 


\subsection{El Parto Experienciado}

El parto huele, el parto se oye -"esa noche, encogidos en un pasillo, oímos los gemidos de mi madre [...]" (Allende 1994: 27)-, el parto tiene un tiempo específico -"el tiempo se congeló en el cuarto y el sol se detuvo sobre las rosas de la terraza, el mundo retuvo el aliento para celebrar el prodigio de esa nueva vida" (Allende 1994: 304)-, en el cual se producen transformaciones corporales que llevan a reformular identidades, expectativas y relaciones.

El parto se narra, se relata:

El clima de tranquila alegría que reinaba en nuestra casa cuando nació Andrea en nada se parecía a mi angustia en ese pabellón de maternidad veinticinco años atrás. A media tarde, Celia hizo una señal, Nicolás la ayudó a subir a la cama y, en menos de un minuto, se materializaron en la habitación los apartados e instrumentos que la matrona traía en su camioneta. Esa muchacha en pantalones cortos pareció envejecer de súbito, le cambió el tono de voz y milenios de experiencias femeninas se reflejaron en su cara pecosa. Lávese las manos y prepárese, que ahora le toca trabajar a usted, me dijo con un guiño. Celia se abrazó a su marido, apretó los dientes y empujó. Y entonces, en una oleada de sangre, surgió una cabeza cubierta de pelo oscuro y un pequeño rostro aplastado y púrpura, que sostuve cómo un cáliz con una mano, mientras con la otra desprendía de un gesto rápido la cuerda azulada que envolvía el cuello. Con otro brutal empeño de la madre apareció el resto del cuerpo de mi nieta, un paquete ensangrentado y frágil, el más extraordinario regalo. (Allende 1998: 303-304).

El parto se recuerda -"Nicolás vino al mundo en un parto laborioso que demoró un par de días y me dejó más recuerdos que todo el año viajando por Europa" (Allende 1994: 148):

Las imágenes del parto de Celia me vuelven a minuto, la veo transpirando, desgarrada por el esfuerzo, mordiéndose los labios, paso a paso por esa larga prueba sin ayuda de calmantes, serena y consciente ayudando a su hija a nacer. La veo en su esfuerzo final, abierta como una herida cuando surge la cabeza de Andrea, oigo su grito triunfal y el sollozo de Nicolás [...] (Allende 1998: 384). 
El parto se baila:

Mi nuera lleva en las venas canciones secretas que marcan el ritmo de sus pasos cuando camina, durante las contracciones jadeaba y se mecía como si escuchara por dentro una irresistible tamborera venezolana. Hacia el final me pareció que en algunos momentos empuñaba las manos y un ramalazo de terror pasaba por sus ojos, pero enseguida su marido encontraba su mirada, le susurraba algo en la clave privada de los esposos y ella aflojaba la tensión. (Allende 1998: 384).

El parto cambia:

Hay un momento en que el viaje iniciado no puede detenerse, ruta vamos hacia una frontera, pasamos a través de una puerta misteriosa y amanecemos al otro lado, En otra vida. El niño entra al mundo y la madre a otro estado de conciencia, ninguno de los dos vuelve a ser el mismo. (Allende 1994: 303).

El parto es ruptura, simbólicamente, corporal, una partición:

Tuve la impresión de caer por un precipicio, ganando impulso y velocidad que, con cada segundo, hasta un estrepitoso final en el cual se me abrieron los huesos y una fuerza telúrica incontrolable empujó a la criatura hacía afuera. (Allende 1994: 184).

Asimismo, tiene que ver con el encuentro, con la vulnerabilidad entendida como elemento central de las relaciones humanas, de entrega, de dependencias múltiples y singulares (Cavarero 2013). Por ello Butler afirma que reconocer la condición de vulnerabilidad significa recuperar la responsabilidad colectiva por la vida corporal del uno y del otro. Así que el parto tiene que ver con las dos interpretaciones etimológicas de raíz latina de vulnerabilidad, vulnus. Por una parte, llaga, lesión y herida implícitas en la idea de violencia; por la otra, también de desnudez, una situación en la cual la piel está desnuda, en la cual no hay muerte, cesa la batalla, y se re-significa la vulnerabilidad del parto como momento ontológico relacional, de tal manera que las características de oblación, sacrificio y dolor no lo resignifican semántica ni políticamente.

El parto es un momento de re-conocimiento ontológico, un inicio, un cuento biográfico, una memoria que teje las primeras relaciones humanas. En el parto 
se observa un cuerpo vivido, un cuerpo en acción, trasformado y transformante, experienciado. Se observa como una fenomenología del cuerpo -Leib-, un cuerpo que está viviendo la política corporal del parto. Así que podemos decir que vivimos corporalmente el parto, que tenemos el parto experienciado, resaltando esta dimensión de vivencia, de las subjetividades que se constituyen en relación entre ellos y a través del relato. Por esto el parto es, asimismo, una estrategia corporal de resistencia, contestación, disidencia y transformación ${ }^{23}$.

\section{Conclusiones}

Nunca pensó que la maternidad caducara, quedarse de pronto vacía y sin un propósito claro para seguir levantándose, vistiéndose

(Belli 2014: 55)

La finalidad de este escrito ha sido la de re-pensar el parto como un evento biográfico-relacional a partir de unas narraciones diferentes -Isabel Allende, Gioconda Belli, Laura Esquivel, pero también Judith Butler, Hannah Arendt, Adriana Cavarero, Monica Sjöö y Niki- en las cuales, en términos estéticos, éticos, sociales y políticos, no se parte del "yo" que oculta, a veces lesiona, engloba, viola o esconde la Alteridad. Dicho con otras palabras, donde no reside la presencia del "T" solipsístico que Virginia Wolf irónicamente describe $^{24}$ :

No es que este "yo" no fuera un "yo" de lo más respetable; honrado y consecuente, puro como una nuez, pulido por siglos de buena educación y buena comida. Pero - aquí volví una página o dos, en busca de una cosa o de otra- lo peor es que a la sombra de la palabra "yo", todo es informe como la niebla. ¿Es eso un árbol? No, es una mujer. (Woolf 1986: 203).

${ }^{23}$ Dolores Juliano observa que cuando decíamos en las manifestaciones de mujeres: "yo también he abortado" o "todas somos adúlteras" no significa que lo hayamos hecho, se reivindicaba el derecho de hacerlo, reivindicación que permite unir y actuar, ejercer presión para modificar las normas, mostrar los límites de un sistema (2006).

${ }^{24}$ Análisis de Adriana Cavarero (2013). 
Sino del enredarse de figuras geométricas que asuman la vulnerabilidad como condición humana, como categoría para construir la relación con la Alteridad.

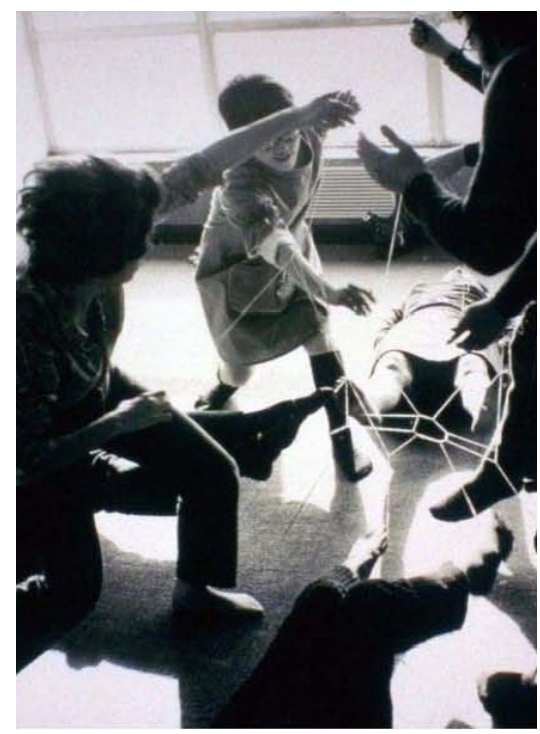

Fig. 4. Lygia Clark, (1969). Estructuras vivas. Cintas elásticas atadas a los pies y a las manos de cuatro personas tumbadas en el suelo. Geografías y redes, espacios y figuras sensoriales.

En definitiva, no tenía el propósito de promover o de conyugar un nuevo temario narrativo, sino de analizar algunos de los relatos sobre el parto debidamente elegidos y realizados en diversas obras de narrativas, para evidenciar que, más allá de utilizar elementos de oposición para describir la experiencia de ser o no madre (Child free, malas madres, etc.), de excusas determinísticas, representaciones iconográficas, o resaltando aún más los límites periféricos del cuerpo humano que no permiten la relación o el nacimiento sino solo en términos de verticalidad, existe un modelo central e indispensable en las relaciones humanas centrado en el reconocimiento del vínculo en la relación ("La Estructuras Vivas" de la Clark). Es decir, un cambio de estructuras en las cuales las mujeres, en sus más profundas diferencias éticas, políticas y ontológicas, toman y dan vida, se inclinan a la Alteridad, generan agency, tejen relaciones, 
biografías y testimonios, representación y protagonismo y devuelven a los y las lectores/as geometrías relacionales a través del parto. Por otra parte, creo que, si la maternidad como experiencia personal está rechazada y tiene derecho de serlo, en el sentido de ser una experiencia no elegida, no deseada, etc., no tenemos que hacerlo también con la maternidad como discurso ontológico relacional, como categoría y modelo teórico de observación de la realidad contemporánea, como indicador de salud, como categoría para comprender los límites de un modelo ontológico individualista en el proceso de salud, atención y enfermedad, en la ética del cuidado, en la política de la crianza o en el problema del sujeto-objeto dentro y fuera del espacio público, y reflexionar desde y con la racionalidad. Aún más, si asumimos cómo, hoy en día, la maternidad es un hecho público, y no privado, ya que está sujeta a un control extremo por parte del sistema biomédico y del saber popular (Hager 2011), negarla, olvidarla, oponerla a, impone una regulación de la memoria tanto individual $^{25}$ y social ${ }^{26}$, como institucional ${ }^{27}$ que resultan imperdonables.

\section{Bibliografía}

1. Allende, I. (1994). Paula. Barcelona: Penguin Random House.

2. Arendt, H. (2006). Alcune questioni di Filosofia morale. Torino: Einaudi.

3. Barrera, A. (2006). La enfermedad. Barcelona: Anagrama.

4. Belli, G. (2014). El intenso calor de la luna. Barcelona: Planeta.

5. Boladeras, M. \& Goberna, J. (eds.) (2017). Bioética de la maternidad. Humanización, comunicación y entorno sanitario. Barcelona: UBe.

6. Brigidi, S. (2009). Políticas públicas de salud mental y migración latina en Barcelona y Génova, Tesis doctoral, Universitat Rovira i Virgili, Tarragona.

7. Brigidi, S. (2016). Haec ornamenta sunt mea. Reflexiones en torno al universo (in)material de la maternidad. Femeris, 1: 148-165.

8. Brigidi, S. \& Comelles, J. (2014) La mirada (auto) etnográfica de tres comadronas y su traducción (cinemato) gráfica. Los vericuetos del yo autoral. Revista de Medicina y Cine, 10(4): 174-182

${ }^{25}$ Mi biografía, mi relato.

${ }^{26}$ La falta de reconocimiento por el trabajo y la ética del cuidado, por ejemplo, o de registro histórico, pensar a las experiencias de las comadronas, a como no se encuentren los textos de Ramona Via en las universidades de Ciencias de la Salud en Catalunya, ni ella se estudie en determinadas asignaturas (Brigidi y Comelles, 2014; Ruíz y Gomis, 2016).

${ }^{27}$ Los numerosos casos de violencia obstétrica, por ejemplo. Incluso Butler observa que se podrían denominar como una memorialización performativa (2014). 
9. Brigidi, S., Cardús, L. \& Ausona, M. (2017). Las autorrepresentaciones del parto. Una experiencia vivencial: "Altres Naixements". In Boladeras, M. \& Goberna, J. (eds.) (2017). Bioética de la maternidad. Humanización, comunicación y entorno sanitari (pp. 155-172). Barcelona: UBe.

10. Butler, J. (2014). Vida precaria, vulnerabilidad y ética de cohabitación. In Saez Tajafuerce, B. (ed.) (2014). Cuerpo, memoria y representación. Adriana Cavarero y Judith Butler en diálogo (pp. 47-80). Barcelona: Icaria.

11. Butler, J. (2002). Cuerpos que importan. Sobre los limites materiales y discursivos del "sexo". Buenos Aires: Paidós.

12. Calero, P. (2015). El parto de Clara. Madrid: Émepe.

13. Callister, L.C. (2004). Making Meaning: Women's Birth Narratives. Journal of Obstetric, Gynecologic, and Neonatal Nursing, 33(4): 508-518.

14. Cardús, L. (2015). Miedo al parto y narrativas intergeneracionales. Una aproximación desde la antropología. Dilemata, 7(18): 129-145.

15. Cavarero, A. (2013). Inclinazioni. Critica delle rettitudine. Milano: Raffaello Cortina Editore.

16. Clark, Lygia (1969). Estructuras vivas. Image.

17. de Saint-Phalle, N., Tinguely, J. \& Per-Olof Ultvedt. (1966). Hon. Sculpture.

18. Donath, O. (2016). \#madres arrepentidas. Una mirada radical a la maternidad y sus falacias sociales. Barcelona: Penguin Random House.

19. Esquivel, L. (1989). Como agua para chocolate. México: Planeta.

20. Esteban, M. L. (2000). La maternidad como cultura. En Perdiguero, E. y Comelles, J. (eds.) Medicina y cultura: Estudios entre la antropología y la medicina (pp. 207-226). Barcelona: Bellaterra.

21. Freixas, L. (2009). Libro de las madres. Zaragoza: 451 Editores.

22. Ferrarotti, F. (2007). Las historias de vida como método. Convergencia, 14(044): $15-40$

23. Forcades, T. (2012). La trinitat avui. Barcelona: L'Abadia de Montserrat.

24. Frankenhaeuser, M., von Wright, M., Collins, A., von Wright, J., Sedvall, G. Swahn, C. (1978). Sex Differences in Psychoneuroendocrine Reactions to Examination Stress. Psychosomatic Medicine, 40(4): 334-343.

25. Hager, T. (2011). Making sense of an untold story: a personal deconstruction of the myth of motherhood. Qualitative inquiry, 7(1): 35 .

26. Himmelweit, S. (1988). Mote than "a woman's right to choose? Feminist review, 29: $38-56$

27. Juliano, D. (2006). Mujeres en prisión: Vulnerabilidades y resistencias. En Impresionadas. XI Jornadas interrelación violencias machistas y VIH. Ponencia III. Recuperado el 10/10/2007 en https : //www.youtube.com/watch? $v=$ jazfiWi3MF4

28. Lagarte, M. (2003). Mujeres cuidadores: entre la obligación y la satisfacción. Sare. Recuperado el 12/09/2016, de http://pmayobre.webs.uvigo.es/textos/marcela_lagarde_y_de_los_rios/ mujeres_cuidadoras_entre_la_obligacion_y_la_satisfaccion_lagarde.pdf 
29. Lévinas, E. (1984). Nomi propri. Genova: Marietti.

30. Lindo, E. (2017). "Ellas lo contaron mejor". Lo cursi ha decaído a favor de las madres que confiesan su falta de vocación. El País. Recuperado el 13/01/2017, de http : //cultura.elpais.com/cultura/2017/02/03/actualidad/1486142911_032324.html

31. Martín, F. (2007). Hon. El cuerpo habitado. Sevilla: Universidad de Sevilla. Recuperado el 05/12/2014, de http://institucional.us.es/revistas/arte/20/27\%20Martin.pdf

32. Ruiz, L \& Gomis, A. (2016). Matronas víctimas de la Guerra Civil Española. Asclepio, 68(2): 159 .

33. Reckitt, H., \& Phelan, P. (2005). Arte y feminismo. Barcelona: Phaidon.

34. Saez Tajafuerce, B. (ed.) (2014). Cuerpo, memoria y representación. Adriana Cavarero y Judith Butler en diálogo. Barcelona: Icaria.

35. Schallman, R. (2007). Parir en libertad. Buenos Aires: Grijalbo.

36. Sjöö, M (1968). God Giving Birth. Painting.

37. Tietjens, D. (2001). The rush to motherhood: pronatalist discourse and women's autonomy. Signs: Journal of women in culture and society, 23(3): 735-773.

38. Valls, C. (2009). Morbilidad diferencial en mujeres mayores de 50 años. XV Seminario de RedCaps. Recuperado el 02/03/2017, de http : //www.caps.cat/images/stories/XI_Seminario_Red caps_2009_Carme_Valls.pdf

39. Villa, S. (2017). Mádre hay más que una: Un relato en primera persona sobre la aventura de la maternidad. Barcelona: Planeta.

40. Woolf, V. (1986). Una habitación propia. Barcelona: Seix Barral.

\section{Author's Biodata}

Serena Brigidi es doctora en antropología de la medicina (URV, 2009), con una tesis sobre migración y salud mental que recibió la mención honorífica del Premio de investigación cultural Marqués de Lozoya (2010). Licenciada en Pedagogía (Università degli Studi di Genova, Italia, 2001). Es profesora colaboradora en la Escuela de Enfermería Sant Pau de la Universitat Autònoma de Barcelona. Miembro investigador del Medical Anthropology Research Center, MARC (URV). Cofundadora del grupo de investigación MATER: Observatorio de las maternidades y paternidades contemporáneas. Entre sus líneas de investigación se incluyen las siguientes: Migración y salud mental; experiencias y narrativas institucionales sobre la atención a la salud mental; género, salud, cuerpo y emociones; estudios de la maternidad: medicalización del parte, embarazo, crianza, lactancia materna y violencia obstetricia. 